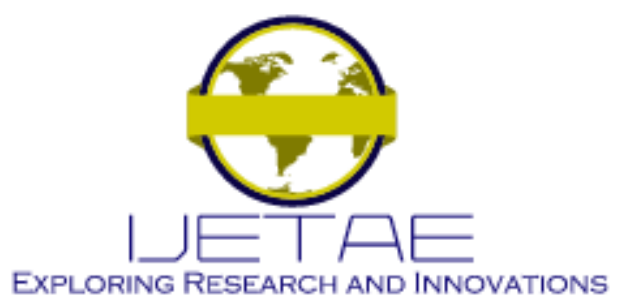

International Journal of Emerging Technology and Advanced Engineering

Website: www.ijetae.com (E-ISSN 2250-2459, Scopus Indexed, ISO 9001:2008 Certified Journal, Volume 11, Issue 06, June 2021)

Manuscript Received: 22 April 2021, Received in Revised form: 25 May 2021, Accepted: 06 June 2021

DOI: 10.46338/ijetae0621_03

\title{
Machine Learning for the Prediction of Returned Checks Closing Status
}

\author{
Mansoor G. Al-Thani ${ }^{1}$, Yin Yang ${ }^{2}$ \\ Information and Computing Technology, College of Science and Engineering, Hamad Bin Khalifa University (HBKU) / Qatar \\ Foundation (QF), P.O. Box 5825, Doha, Qatar
}

\begin{abstract}
Data mining is one of the most valuable tools for several applications, especially in banking sector. It can be used in risk analysis of loans, detecting fraud in real time and classifying customers' interests for retention and services purposes. The main objective of this research is to develop a predictive model that can expect the closure status of returned cases in Qatar. This would be of valuable help for the banking sector as well as The Ministry of Justice. The banking sector aims at anticipating when the check will be paid and the Ministry of Justice holds the burden to assign more judges to look into cases of this kind. To produce the predictive model, four-year worth of data (2014-2017) on returned checks as registered at the Police Criminal System in The State of Qatar were obtained. The data was first cleaned from improper input and the attributes collected were reduced from 16 to 10 eliminating those with the lowest to no correlation. Seven classifiers were used in Python code to generate the prediction model: Random Forest (RF), Gaussian Naive Bayes (NB), kNearest Neighbor (KNN), Logistic Regression (LR), Decision Tree Classifier (CART), Linear Discriminant (LD) and Support Vector Machine (SVM). The evaluation of the classifiers was based on three main criteria: accuracy, running time and memory usage. The results show that SVM was not able to converge to any output while RF was the most accurate with $84.4 \%$. Moderate performance in all three criteria was obtained by KNN and LR classifiers, while CART had the second best accuracy with moderate running time and memory usage. It was also found that the size of dataset and the correlation between attributes hugely affect the performance of each algorithm. Moreover, a logarithmic correlation between the accuracy and running time of the classifiers was obtained with $R 2$ of 0.94 . To this end, several recommendations for future work have been proposed to facilitate the use of such predictive models with high confidence in Qatar.
\end{abstract}

Keywords - Data Mining, Deep Learning, Machine Learning, Python, Prediction Model, Returned Checks, Qatar

\section{INTRODUCTION}

Data mining and machine learning have been utilized in several fields such as biomedical studies [1], health care [2], sales and marketing, customer relationship management [3] and traffic classification [4]. Nevertheless, banking sector has found tremendous benefit from data mining algorithms and applications in loan risk estimates, marketing, credit analysis, cash management, forecasting operations and software support [5][6][7][8].

Recent research has focused on creating algorithms to solve particular problems in datasets [9]. Today, the maturity of these techniques coupled with experienced personnel to perform the task has made these technologies of great value in banking sector as well as many other applications. Some of these algorithm classifiers are Random Forest (RF) [10][11], Gaussian Naive Bayes (NB) [12], k-Nearest Neighbor (KNN) [13], Logistic Regression (LR) [14], Decision Tree Classifier (CART) [15][16], Linear Discriminant (LD) [17] and Support Vector Machine (SVM) [18][19].

Several works have been published to evaluate the performance of these classifiers based on their accuracy, stability, running time and memory usage [1][11][20][21] Nevertheless, it was concluded that no single classifier can rank the best in all criteria. Moreover, the classifier performance is greatly affected by the size of data set and the correlation between the attributes in the data mined, among other factors.

Data mining process consists of three phases: data collection and preparation, the actual mining process, and then the interpretation of the results [5] Another step can be added related to the validation of the model if prediction capabilities were the main output of the data mining process [22][23] 


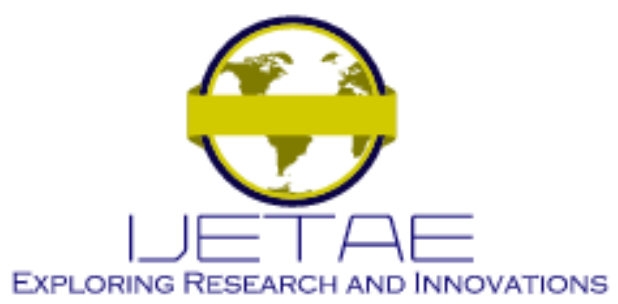

International Journal of Emerging Technology and Advanced Engineering

Website: www.ijetae.com (E-ISSN 2250-2459, Scopus Indexed, ISO 9001:2008 Certified Journal, Volume 11, Issue 06, June 2021)

Chitra et al., [24] have summarized the top ten frauds that have been reported by the banks in India and worldwide. These include credit cards, deposits - saving accounts, internet banking, housing loans, term loans, cash transactions, cash credit accounts, ATM / debit cards and checks. Amongst these bank-related issues, return checks is a critical problem. A returned or bounced check is a check that was used for payment but was not processed because the person who wrote it did not have sufficient funds available in his/her account to cover the payment. In this case, when an account has insufficient funds, the check writer's bank will reject the payment request and return the check (or the electronic request) to the payee's bank. Instead of sending money to the payee, the request for payment "bounces" back [25].

Although the problem of returned checks is a universal issue, Qatar has witnessed an increase in the number of returned checks due to insufficient funds. It was reported recently that Qatari courts receive about 20,000 checksrelated cases annually with the majority of the cases in the courts being related to civil and commercial disputes, says a senior Qatari lawyer [26] Among several types of commercial fraud cases related to finance, properties, forging, funding, and rents, bounced or returned checks cases are on the top of the list according to data released by the Supreme Judiciary Council recently [26]. Qatar Central Bank identified several reasons for returned checks that include: the lack of available balance in the bank account that is sufficient to pay the amount in the check, mismatch in dates on which the check is to be paid, mismatch of signature between what the bank acknowledges and the one that appears on the check, outdated checks (checks submitted for collection after about six months of the written date of collection), among other reasons.

In a step to be taken by The Qatar Central Bank, the banks operating in Qatar has been instructed to enhance their measures to address the issue of returned checks giving companies and individuals chances to rectify their financial status. One of the added complications of this case is the need for more judges to serve in order to deal with this increase in returned checks. The only way to settle these bounced checks is the arrangement to actually pay the due amount that was mentioned in the check originally.

In this work, data on returned check cases as registered at the Police Criminal Station was collected from 20142017. The data was cleaned, reduced and formatted to be ready for use in Python code.
Seven classifiers were used to develop a prediction model that is capable to expect the closure status of each case. The classifier performance was evaluated against three main criteria: accuracy, speed and memory usage. Cross validation was then performed to evaluate the accuracy of the model.

\section{Methodology}

\section{A. Data Collection}

The attributes in this study (Table 1) were collected from the database of the Police Criminal System (PCS) at The Ministry of Interior. This system is the sole source of all information related to the status of returned checks that was claimed as open/ partially paid or closed cases at the police station. The sample data has been taken to cover 4 years between 2014-2017, both years inclusive. Given the sensitivity nature of such data and following the privacy protection laws, the identification data of the individuals such as names and ID numbers were removed.

The supplementary Information (section A) includes all the detailed attributes that were considered in this study. The raw data was provided in a flat-file format (excel sheet) and then several steps were followed to clean the data before using them in Python.

TABLE I

TABLE 1 THE DETAILS AGAINST EACH ATTRIBUTE AS COLLECTED.

\begin{tabular}{|l|l|l|}
\hline Attribute Abbreviation & $\begin{array}{l}\text { Attribute } \\
\text { Description }\end{array}$ & $\begin{array}{l}\text { Relevant (R) } \\
\text { Irrelevant } \\
\text { (IR) }\end{array}$ \\
\hline SYSTEM_INFO & $\begin{array}{l}\text { A code related to } \\
\text { the PCS system }\end{array}$ & IR \\
\hline CASE_ID & Case number & $\mathrm{R}$ \\
\hline CHEQUE_SEQ & $\begin{array}{l}\text { Check sequence } \\
\text { number }\end{array}$ & IR \\
\hline PERSON_INFO & Person Information & $\mathrm{R}$ \\
\hline PERSON_ID & $\begin{array}{l}\text { Person } \\
\text { Identification } \\
\text { number }\end{array}$ & $\mathrm{IR}$ \\
\hline DATE_OF_BIRTH & Date of birth & $\mathrm{R}$ \\
\hline PERSON_AGE & Person's age & $\mathrm{R}$ \\
\hline MARITAL_CODE & Marital status code & $\mathrm{R}$ \\
\hline GENDER_CODE & Male/Female & $\mathrm{R}$ \\
\hline RELIGION_CODE & Religion code & $\mathrm{R}$ \\
\hline
\end{tabular}




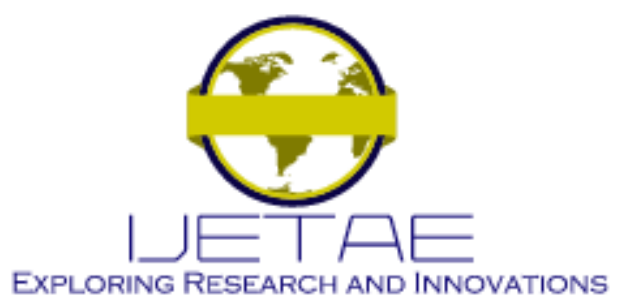

International Journal of Emerging Technology and Advanced Engineering

Website: www.ijetae.com (E-ISSN 2250-2459, Scopus Indexed, ISO 9001:2008 Certified Journal, Volume 11, Issue 06, June 2021)

\begin{tabular}{|c|c|c|}
\hline EDUCATION_CODE & Level of education & IR \\
\hline NATIONALITY_CODE & Nationality & $\mathrm{R}$ \\
\hline PROF_CODE & Profession/job & IR \\
\hline CASE_INFO & $\begin{array}{l}\text { Information related } \\
\text { to the open case }\end{array}$ & IR \\
\hline CASE_START_DATE & $\begin{array}{l}\text { The date at which } \\
\text { the case was } \\
\text { reported at PCS }\end{array}$ & IR \\
\hline CASE_NO & $\begin{array}{l}\text { The number given } \\
\text { to the case }\end{array}$ & IR \\
\hline CASE_YEAR & $\begin{array}{l}\text { The year the case } \\
\text { was reported }\end{array}$ & $\mathrm{R}$ \\
\hline CHEQUE_INFO & $\begin{array}{l}\text { Information about } \\
\text { the check }\end{array}$ & IR \\
\hline BANK_CODE & Bank code & $\mathrm{R}$ \\
\hline CHEQUE_AMOUNT & Amount of check & $\mathrm{R}$ \\
\hline CHEQUE_PAYED_AMOUNT & $\begin{array}{l}\text { Amount paid } \\
\text { completely or } \\
\text { partially }\end{array}$ & $\mathrm{R}$ \\
\hline CHEQUE_CURRENCY_CODE & $\begin{array}{l}\text { Currency as } \\
\text { reported in the } \\
\text { check }\end{array}$ & $\mathrm{R}$ \\
\hline CASE_CLOSE_FLAG & If case is closed & $\mathrm{R}$ \\
\hline CASE_CLOSE_DATE & $\begin{array}{l}\text { Date when the case } \\
\text { was closed }\end{array}$ & $\mathrm{R}$ \\
\hline NUMBER_DEPS & No. of dependents & $\mathrm{R}$ \\
\hline SYSTEM_INFO & $\begin{array}{l}\text { A code related to } \\
\text { the PCS system }\end{array}$ & IR \\
\hline BANK_CODE & Bank code & $\mathrm{R}$ \\
\hline CHEQUE_AMOUNT & Amount of check & $\mathrm{R}$ \\
\hline CHEQUE_PAYED_AMOUNT & $\begin{array}{l}\text { Amount paid } \\
\text { completely or } \\
\text { partially }\end{array}$ & $\mathrm{R}$ \\
\hline CHEQUE_CURRENCY_CODE & $\begin{array}{l}\text { Currency as } \\
\text { reported in the } \\
\text { check }\end{array}$ & $\mathrm{R}$ \\
\hline CASE_CLOSE_FLAG & If case is closed & $\mathrm{R}$ \\
\hline CASE_CLOSE_DATE & $\begin{array}{l}\text { Date when the case } \\
\text { was closed }\end{array}$ & $\mathrm{R}$ \\
\hline NUMBER_DEPS & No. of dependents & $\mathrm{R}$ \\
\hline
\end{tabular}

\section{B. Data Cleaning}

Data cleaning is one of the main steps and is considered a big job before data mining process can take place [27]. Data cleaning involves identifying missing data values, noise and inconsistencies that would affect the accuracy of the data and hence the patterns predicted or obtained [28]. The following subsections show the type of data values and the way we deal with it for the purpose of data cleaning.

\section{Unknown Values}

The first step in our data cleaning was to identify any discrepancy due to unknown values. Some sources of discrepancy can be due to poor data entry forms including human error in data entry or data decay due to outdated addresses or people who permanently left the country. Other sources of discrepancy were identified due to system errors that might have happened from time to time or errors in the instruments and devices that record the data.

Hence, based on our knowledge with the appropriate type of data including the domain and type of data that would attribute to our research, the values that would fall within unacceptable range, outliers and errors were omitted. Moreover, the codes of the banks were checked, the form of date entered and any discrepancy was removed. Examples of the data cleaning performed are given in the Supporting Information, section (B).

\section{Feature Redefinition}

Some attribute values should be entered to python as float (10.0) instead of using digit (10).

\subsection{Data Visualization and Scaling}

At the beginning we started with 16 attributes (Fig. 1), then we reduced them to 10 attributes based on the most correlated attributes as per Fig. 2. 


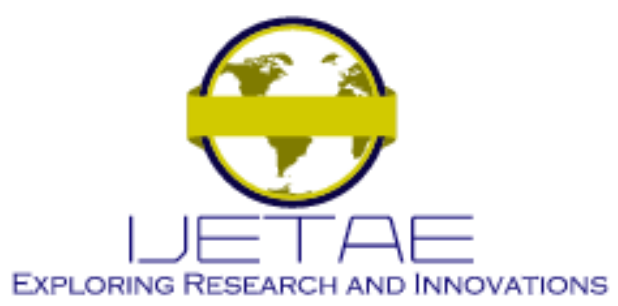

International Journal of Emerging Technology and Advanced Engineering

Website: www.ijetae.com (E-ISSN 2250-2459, Scopus Indexed, ISO 9001:2008 Certified Journal, Volume 11, Issue 06, June 2021)

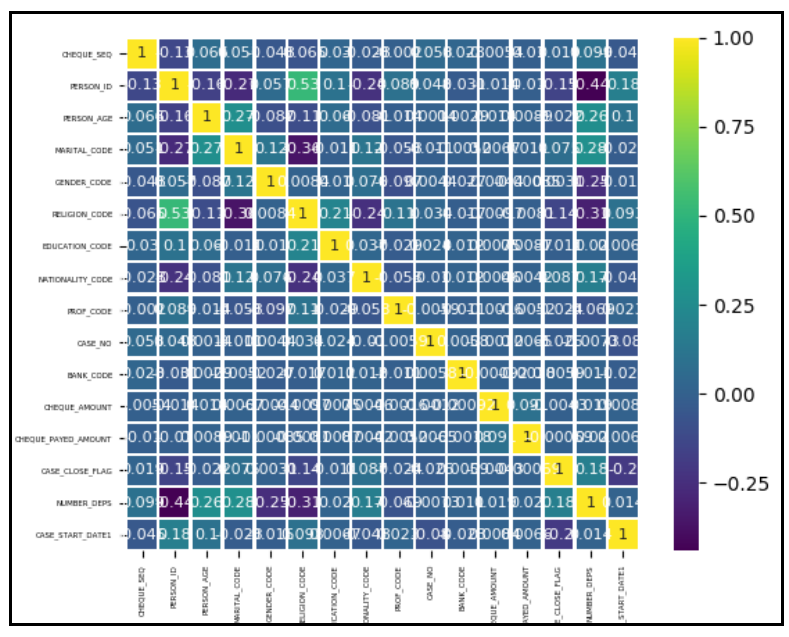

Fig. 1 The first set of data including all relevant attributes.

As can be seen from Fig. 1, there is generally very low correlation between the 16 attributes that we started with. The level of correlation between the attributes is an important factor that can be used to decide on the use of certain algorithms and avoid others. In a recent study by Zhang et al. [1], the authors used seven algorithms to study their suitability for different data sets that have different characteristics. The seven algorithms were C4.5, SVM, AdaBoost $(\mathrm{AB})$, k-nearest neighbor $(\mathrm{KNN})$, naïve Bayes (NB), random forest (RF) and logistic regression (LR) model. They studied the applicability of each algorithm against several quantitative indices that include the size of data set, dimension of the dataset and degree of correlation between the variables [1]. Their study concluded that for datasets with low correlation between its attributes, KNN, C4.5, $\mathrm{AB}$ and $\mathrm{RF}$ are the most suitable.

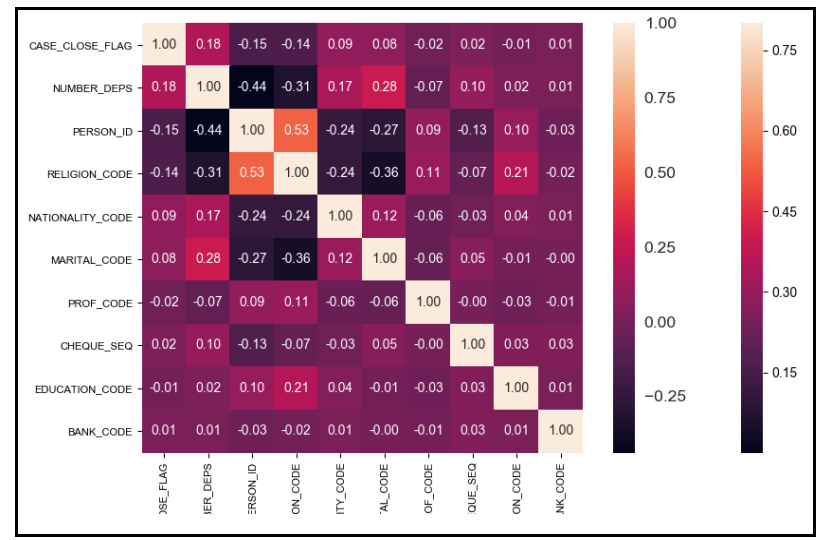

Fig. 2. The final ten attributes that were included in the model.
Hence, the number of attributes was reduced from 16 to 10 for simplicity. A more focused look at Fig. 2, it is noticed that the correlation between the attributes in general is low as explained earlier. The highest correlation $(0.53)$ was found between the person ID and the religion code. This might be related to a certain system when the ID number is issued for any person in Qatar to have a correlation with their religion.

\section{TABLE 2}

QUANTIFICATION OF THE CHARACTERISTICS OF THE DATA SET AFTER REDUCING THE ATTRIBUTES TO 10.

\begin{tabular}{|l|c|}
\hline Quantification Index & Value/ Characteristic \\
\hline Sample size & 100,000 \\
\hline Number of attributes & 10 \\
\hline Level of correlation & low \\
\hline Maximum correlation coefficient & 0.53 \\
\hline Minimum correlation coefficient & 0.01 \\
\hline $\begin{array}{l}\text { The two attributes with highest } \\
\text { correlation }\end{array}$ & $\begin{array}{c}\text { Person ID and Person } \\
\text { Religion }\end{array}$ \\
\hline
\end{tabular}

\section{RESULTS AND DisCUSSION}

Python code as shown in Supporting Information (section C) was used in this project [29][30][31] to run 6 classifiers as shown in Table 3 in addition to the Support Vector Machine classifier which did not yield any results as it took very long time without convergence.

TABLE 3

Performance EVAluAtion OF THE ALgORITHMS USED IN THIS PROJECT.

\begin{tabular}{|l|c|c|c|c|}
\hline Algorithm & Abbreviation & Accuracy & $\begin{array}{c}\text { Running } \\
\text { time (s) }\end{array}$ & $\begin{array}{c}\text { Memory } \\
\text { usage (Mb) }\end{array}$ \\
\hline $\begin{array}{l}\text { Random } \\
\text { Forest }\end{array}$ & RF & 0.844632 & 31 & 270 \\
\hline $\begin{array}{l}\text { Decision } \\
\text { Tree } \\
\text { Classifier }\end{array}$ & CART & 0.821753 & 14 & 345 \\
\hline $\begin{array}{l}\text { K-Nearest } \\
\text { Neighbor } \\
\text { Classifier }\end{array}$ & KNN & 0.696919 & 3 & 290 \\
\hline $\begin{array}{l}\text { Linear } \\
\text { Discriminant } \\
\text { Analyst }\end{array}$ & LDA & 0.605033 & 1 & 350 \\
\hline $\begin{array}{l}\text { Logistic } \\
\text { Regression }\end{array}$ & LR & 0.606532 & 7 & 340 \\
\hline $\begin{array}{l}\text { Gaussian } \\
\text { Naïve Bayes }\end{array}$ & NB & 0.526442 & 0.5 & 275 \\
\hline
\end{tabular}




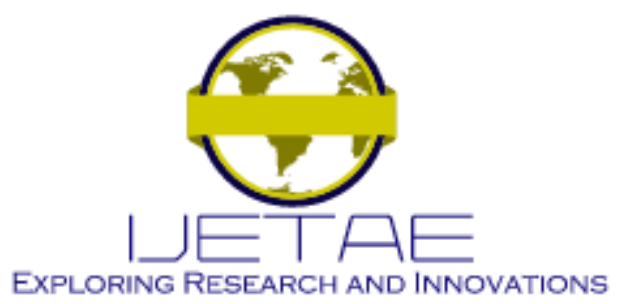

International Journal of Emerging Technology and Advanced Engineering

Website: www.ijetae.com (E-ISSN 2250-2459, Scopus Indexed, ISO 9001:2008 Certified Journal, Volume 11, Issue 06, June 2021)

It can be seen from Table 3 and Fig. 3 that the accuracy of the algorithms used ranges between $52.6 \%$ and $84.4 \%$.

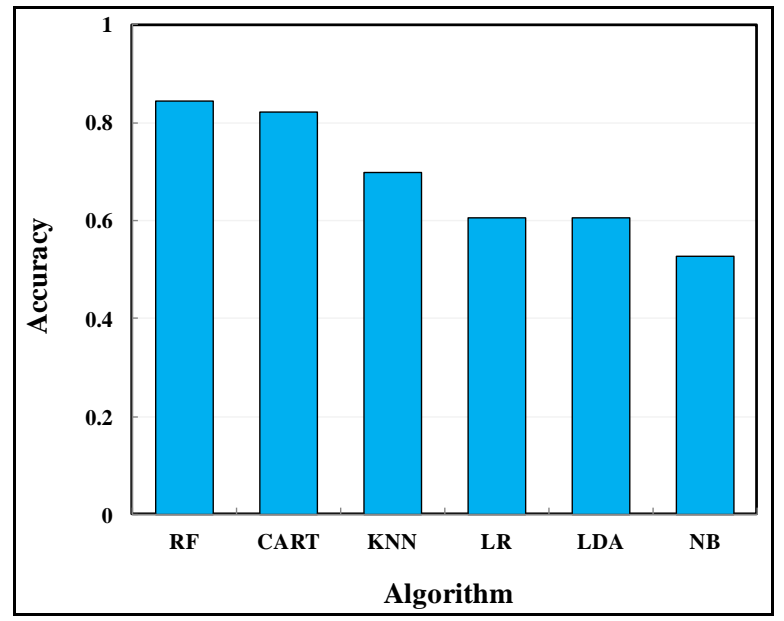

Fig. 3. The accuracy of the algorithms used in this project.

It can be seen that the RF classifier has achieved the highest accuracy. This is expected as it has been reported that Random Forest is appropriate for high dimensional data modeling because it can handle missing values and can handle continuous, categorical and binary data [32]. Moreover, the RF has proved to be applicable for small as well as large data sets. It is also highly recommended for datasets with low correlated attributes like our case [1]. These features make the model interpretability and prediction accuracy provided by Random Forest very unique among popular machine learning methods. Accurate predictions and better generalizations are achieved due to utilization of ensemble strategies and random sampling which are both characteristics of RF.

The CART had the second best accuracy with close value to RF. While CART can perform well with low correlated datasets, it is not suitable for large datasets. This will be seen more clearly when the algorithms are compared in terms of memory usage and running time. On the other hand, although $\mathrm{KNN}$ is well suited for large datasets [1], it did not perform as expected with our data. This might be attributed to the fact that $\mathrm{KNN}$ performs badly when different attributes affect the outcome to different extents or when some attributes are completely irrelevant as all attributes contribute equally to the distance formula [28].
In our case, examples of attributes that were included in the model that are considered irrelevant to the output predicted can be the person ID, religion code and profession code.

The lowest accuracy was obtained by Gaussian NB. NB is a simple algorithm that should be adopted for small datasets with high correlation, contrary to the nature of our data sets which is very large with poor correlating attributes.

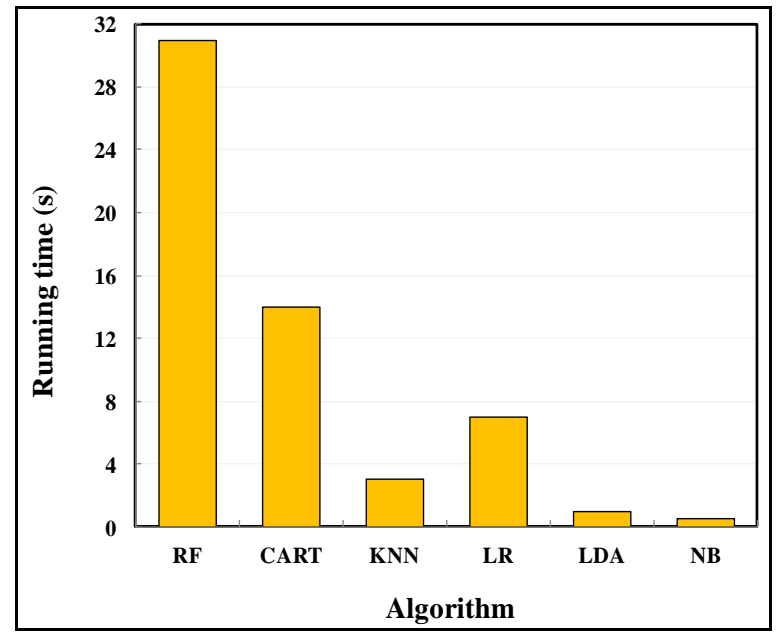

Fig. 4. The running time of the algorithms used in this project.

Fig. 4 shows the running time of each classifier that has been used in this study. The running time is considered an important factor when classifiers are evaluated to perform a task. For instance, we tried to use SVM but the running time took long before the computer freezes without convergence to any output. This is expected as SVM is reported not to be suitable for large datasets or when attributes have low correlation [28] as per our case (refer to Fig. 1 and 2). To further investigate if there is a relation between accuracy and running time, the two have been plotted as shown in Fig. 5, excluding one outlier point which is related to LR. The relation can be represented by a logarithmic equation with R2 value of 0.9493 which indicates high fitness of the model. It must be noted that this relation might work well for our dataset but not for another. 


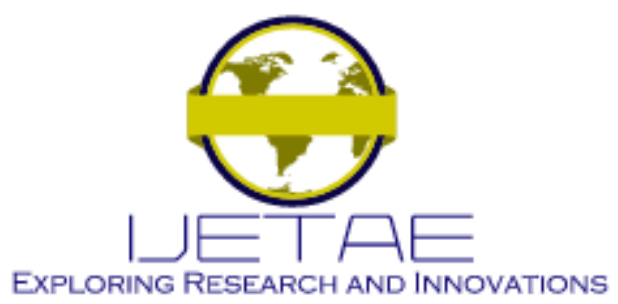

International Journal of Emerging Technology and Advanced Engineering

Website: www.ijetae.com (E-ISSN 2250-2459, Scopus Indexed, ISO 9001:2008 Certified Journal, Volume 11, Issue 06, June 2021)

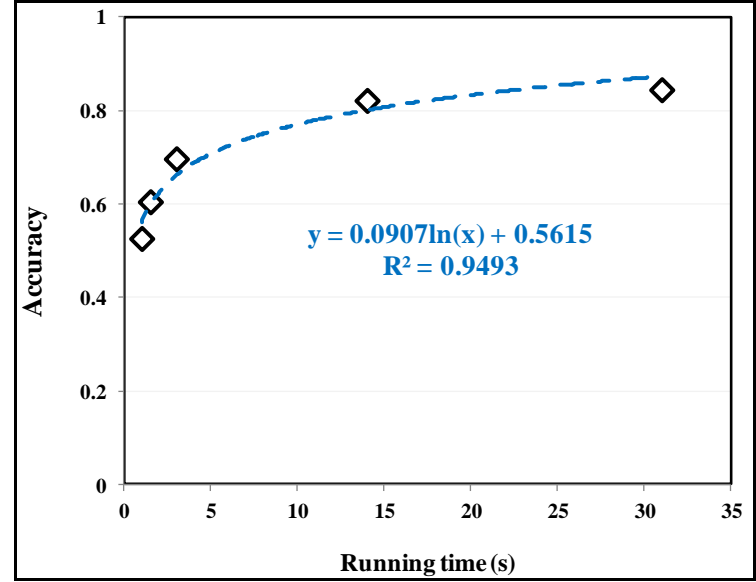

Fig. 5. The relation between running time and accuracy of each classifier.

The next factor that we studied is the memory usage of each classifier. This is a critical factor as it relates to the complexity of the set up needed to perform these predictive models. Fig. 6 shows that there is little difference in the memory usage requirements between all the classifiers which indicates that the accuracy and running time are more significant for the evaluation of the used classifiers in this project. Nevertheless, it should be noted that RF has the privilege of using the least memory (about $270 \mathrm{Mb}$ ) compared with the next accurate classifier (CART) which required about $345 \mathrm{Mb}$. Moreover, CART has shown slower performance than NB in agreement with what has been reported in previous studies [21].

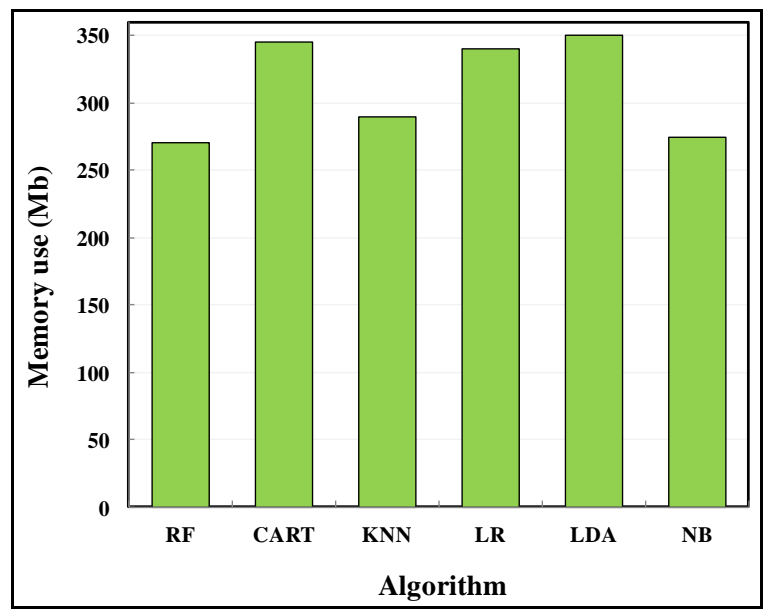

Fig. 6. The memory usage of the algorithms used in this project.
To have an overall look at the performance of each classifier based on the previous three factors (accuracy, running time and memory usage compared with each others), Fig. 7 shows the ranks from 1-6.

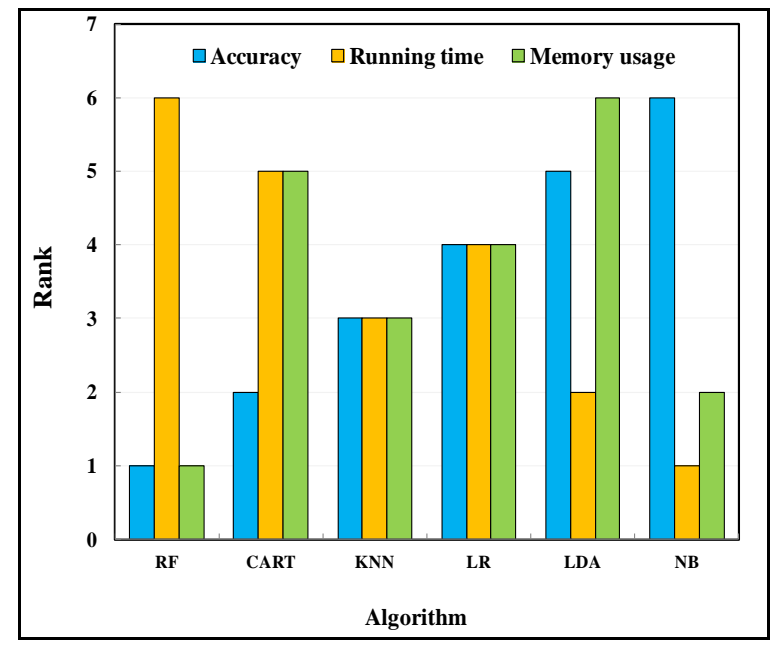

Fig. 7 The rank of the algorithms used in this study.

It can be seen that KNN and LR both have moderate performance in terms of accuracy, running time and memory usage. On the other hand, RF performed the best in terms of accuracy and memory usage but ranked the last in running time. Hence, it can be indicated that no algorithm can be declared the best for all criteria for this dataset, although RF can be nominated as a first choice. This conclusion is similar to previous works in different areas, concluding that no single algorithm can be easily detected to perform the best in all factors exclusively [1][9][21]

\section{Data Validation}

To test and evaluate the algorithms, k-Fold Cross Validation has been applied to confirm the scores of the algorithms that were obtained. In the process of algorithm evaluation using k-Fold cross validation, the dataset is divided into $\mathrm{k}$ subsets. Each time, one of the $\mathrm{k}$ subsets is used as the test set and the other k-1 subsets are considered as the training set. Performance statistics are calculated across all $\mathrm{k}$ trials to provide a good indication of how well the classifier will perform on unseen data.

In our case, we used $\mathrm{k}=10$ to evaluate three standard metrics that are used in this validation [21]): 


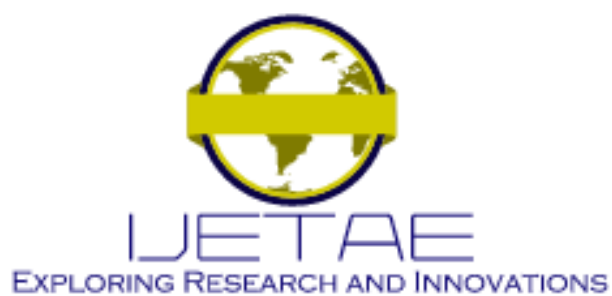

International Journal of Emerging Technology and Advanced Engineering

Website: www.ijetae.com (E-ISSN 2250-2459, Scopus Indexed, ISO 9001:2008 Certified Journal, Volume 11, Issue 06, June 2021)

- Accuracy: the percentage of correctly classified instances over the total number of instances. In other words, it simply indicates the ratio of correctly predicted observations to the total observations. In general, high accuracy would indicate that the model is performing well, but this indication is not enough to generate such a conclusion without looking at the other two parameters; the precision and recall (the true positive rate). In our case, the accuracy of the model was 0.83 which means that our model is approximately $83 \%$ accurate.

- Precision: is the ratio of correctly predicted positive observations to the total predicted positive observations. High precision relates to the low false positive rate. We have got 0.83 precision which is pretty good.

- Recall (or true positive rate): the number of class members classified correctly over the total number of class members. In our model, we obtained 0.83 as recall which is good as it is above 0.50 .

- F1 score: is the weighted average of Precision and Recall. Therefore, this score takes both false positives and false negatives into account. In our model we got 0.83 for F1 score.

\section{CONCLUSIONS}

Data mining techniques can be of great help in many vital sectors such as medicine, business, and security among others [7]. However, data mining and machine learning are becoming strategically important in banking sector where data can be summarized to provide valuable information. Nowadays, banks and financial institutions aim at acquiring new customers, being notified about fraud detection in real time and adding a lot more value to existing products and services.

One of the main issues that are faced by banks around the world as well as in The State of Qatar is the returned or bounced checks problem. The banks are not able to identify who would pay the returned check, if it would be paid in full or partially or remain suspended for significant period of time.

In this work, several classifiers were used in Python Code to develop a predictive model to identify the status of the returned check case. The seven classifiers used in this work are Random Forest, Gaussian Naive Bayes, k-Nearest Neighbor, Logistic Regression, Decision Tree Classifier, Linear Discriminant and Support Vector Machine. The algorithms performance was evaluated against three criteria: accuracy, memory usage, and running time.
It was found that feature reduction techniques that we followed after cleaning the data are able to greatly reduce the feature space, while only minimally impacting classification accuracy and at the same time significantly increasing computation performance. This is especially important in similar research cases where attributes have low correlation and hence, their reduction from 16 attribute to 10 was advantageous to the process. Moreover, although several studies have been reported about the use of data mining with different classifiers in banking sector, the work related to predicting the case closure status of the checks in Qatar has not been studied before. The process of defining appropriate features, performing feature selection and the influence of this on classification and computation performance for specific tasks is not straight forward. It is of critical importance to mention that no algorithm can obtain the best rank in every criterion. It mainly depends on the data set type and correlation between attributes. Support Vector Machine was not able to converge with any output and caused the computer to freeze due to large datasets. Random Forest performed the best for accuracy and memory usage but not for running time. Moderate performance in all three criteria was obtained by k-Nearest Neighbor and Logistic Regression classifiers. Decision Tree Classifier had the second best accuracy with moderate running time and memory usage. Moreover, it was found that there is a logarithmic correlation between the accuracy and running time of the classifiers with R2 of 0.94. It is also observed that some classifiers did not perform as expected due to the nature of our dataset which is large with very low correlated attributes. The cross validation of the Decision Tree Classifiers obtained 83\% accuracy.

Since this work is the first of its type in this domain, several avenues and recommendations for future work can be suggested. First, the data filled for each attribute should be updated such as the profession and level of education, the address and residency status if changed. More in-depth evaluation of as to why different algorithms exhibit different classification accuracy and computational performance. The stability of the prediction can be challenged by trying different combinations of attributes that we started with (16 attributes) before being reduced to 10. Ways to improve the running time of the most accurate algorithm (Random Forest) can be investigated. Different methods for sampling and constructing training datasets can be tried to verify the model. 


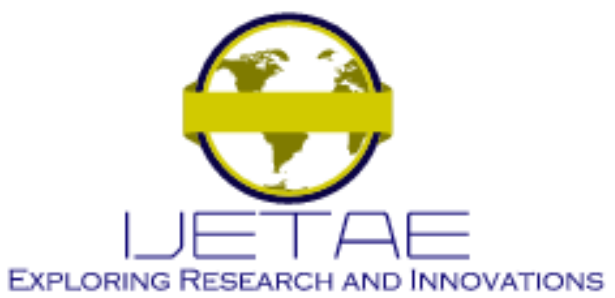

International Journal of Emerging Technology and Advanced Engineering

Website: www.ijetae.com (E-ISSN 2250-2459, Scopus Indexed, ISO 9001:2008 Certified Journal, Volume 11, Issue 06, June 2021)

\section{Abbreviations}

SVM: Support Vector Machine; kNN: k-Nearest Neighbor; NB: Naïve Bayes; RF: Random Forest; LR: Logistic Regression; SVC: Support Vector Classification.

\section{Authors' contributions}

MA did all of the data analysis and wrote the manuscript, DY supervised the work, read and approved the final manuscript.

\section{Acknowledgements}

We acknowledge the support of the Police Criminal System (PCS) at The Ministry of Interior- State of Qatar for providing the raw dataset used in this work.

\section{Competing interests}

The authors declare that they have no competing interests.

\section{REFERENCES}

[1] Zhang Y, Xin Y, Li Q, Ma J, Li S, Lv X, et al. Empirical study of seven data mining algorithms on different characteristics of datasets for biomedical classification applications. Biomed Eng Online 2017;16:1-15. doi:10.1186/s12938-017-0416-х.

[2] Divya T, Agarwal S. A survey on data mining approaches for healthcare. Int J Bio-Science Bio-Technology 2013;5:241-66.

[3] Berry, Michael J. A. ; Linoff GS. Data mining techniques. vol. 25. 1996.

[4] Williams N, Zander S, Armitage G. A preliminary performance comparison of five machine learning algorithms for practical IP traffic flow classification. ACM SIGCOMM Comput Commun Rev 2006;36:5

[5] Jafar Hamid A, Ahmed TM. Developing Prediction Model of Loan Risk in Banks Using Data Mining. Mach Learn Appl An Int J 2016;3:1-9.

[6] Zakirov D, Montselidze N. Application of Data Mining in the Banking Sector. J Tech Sci Technol 2015;4:13-6.

[7] Bhambri V. Application of Data Mining in Banking Sector. Int J Comput Sci Technol 2011;4333:199-202.

[8] Berson A, Smith S, Thearling K. Building Data Mining Applications for CRM. McGraw-Hill Professional; 1999.

[9] Kotthoff L, Gent IP, Miguel I. An Evaluation of Machine Learning in Algorithm Selection for Search Problems. Fourth Int Symp Comb Search 2011;25:257-70.

[10] Kulkarni V, Sinha P. Random Forest Classifiers: A Survey and Future research Directions. Int J Adv Comput 1997;36:1144-53.

[11] Kulkarni VY, Sinha PK. Effective Learning and Classification using Random Forest Algorithm. Int J Eng Innov Technolgy 2014;3:26773.
[12] Nickisch H, Rasmussen CE. Approximations for binary Gaussian process classification. J Mach Learn Res 2008;9:2035-2078.

[13] Kataria A, Singh MD. A Review of Data Classification Using KNearest Neighbour Algorithm. Int $\mathbf{J}$ Emerg Technol Adv Eng 2013;3:354-60.

[14] Hellevik O. Linear versus logistic regression when the dependent variable is a dichotomy. Qual Quant 2009;43:59-74.

[15] Loh W. Classification and regression trees. Data Min Knowl Discov 2011;1:14-23.

[16] Chao W. Machine Learning Tutorial. DispEeNtuEduTw 2011.

[17] Chikara R, McKeon J. Linear discriminant analysis with misallocation in training samples. J Am Stat Assoc 1984;79:899_ 906.

[18] Meyer D. Support vector machines. Engineering 2009;1:1-8.

[19] Alabdulmohsin I, Gao X, Zhang X. Support vector machines with indefinite kernels. JMLR Work. Conf. Proceeding, 2014, p. 32-47.

[20] Thangaparvathi B, Anandhavalli D. An improved algorithm of decision tree for classifiying large data set based on rainforest framework. IEEE 2010;10:800-5.

[21] Pandya R, Pandya J. C5.0 Algorithm to Improved Decision Tree with Feature Selection and Reduced Error Pruning. Int J Comput Appl 2015;117:18-21.

[22] Glowacki J. Effective model validation using machine learning Model validation has been a key focus that rely on models for underwriting, learning techniques. Milliman White Pap 2017:1-4.

[23] Lu Y. Deep neural networks and fraud detection 2017.

[24] Chitra K, Subashini B. Data Mining Techniques and its Applications in Banking Sector. Int J Emerg Technol Adv Eng 2013;3:219-26.

[25] Pictchard J. Learn about bounced checks. Balanc 2017. https://www.thebalance.com/bounced-check-315339.

[26] Osman M. Cases of bounced checks on rise in Qatar. Penins Qatar 2017. https://www.thepeninsulaqatar.com/article/19/02/2017/Casesof-bounced-cheques-on-rise-in-Qatar.

[27] Raman V, Hellerstein JM. Potter's Wheel: An Interactive Data Cleaning System. 27th VLBD Conf., vol. 01, 2001, p. 381-90.

[28] Han J, Kamber M. Data Mining: Concepts and Techniques. Second Edi. San Francisco, USA: Morgan Kaufmann Publishers-Elsevier; 2006.

[29] Nielsen A. Data Mining with Python. 2017.

[30] Grace E, Hall J, Redmiles E. Detecting Fraud , Corruption , and Collusion in International Development Contracts: The Design of a Proof-of-Concept Automated System. IEEE Int. Conf. Big Data, 2016, p. 1444-53.

[31] Gupta S. Deep Learning vs traditional Machine Learning algorithms used in Credit Card Fraud Detection. National College of Ireland, 2015.

[32] Ali J, Khan R, Ahmad N, Maqsood I. Random forests and decision trees. IJCSI Int J Comput Sci Issues 2012;9:272-8. 